\title{
Corrigendum: Seismic precursors linked to highly compressible fluids at oceanic transform faults
}

\author{
Louis Géli, Jean-Michel Piau, Vincent Maury, Delphine Fitzenz, Robert Dziak, Quentin Coutellier, Pierre Henry, \\ Daniel Broseta, Matthew Steele-Maclnnis and Thomas Driesner
}

Nature Geoscience 7, 757-761 (2014); published online 14 September 2014; corrected after print 24 December 2015.

The version of this Letter originally published described hydrothermal fluids circulating within oceanic fracture zones near ridgetransform intersections as super-critical fluids. However, Daniel Broseta, Matthew Steele-MacInnis and Thomas Driesner pointed out that, even if this term is of common use in the scientific literature, this description is incorrect and potentially misleading for multicomponent fluids such as seawater. In addition, some of the values of compressibility cited in the original Letter were incorrect. Correct values of isothermal compressibility of seawater are one order of magnitude higher compared with those used in the original manuscript and exhibit a sharp discontinuous increase near dew-point conditions. As a consequence, the effect of variations in fluid compressibility on seismicity is enhanced. This strengthens our confidence in the Piau-Maury-Fitzenz model. Figures 2 and 3 (new versions shown below) and some of the calculations invoking the real fluid properties at the relevant conditions have been corrected in all online versions of the Letter. Daniel Broseta, Matthew Steele-MacInnis and Thomas Driesner have been added to the author list in recognition of their contributions to these amendments.

Figure 2

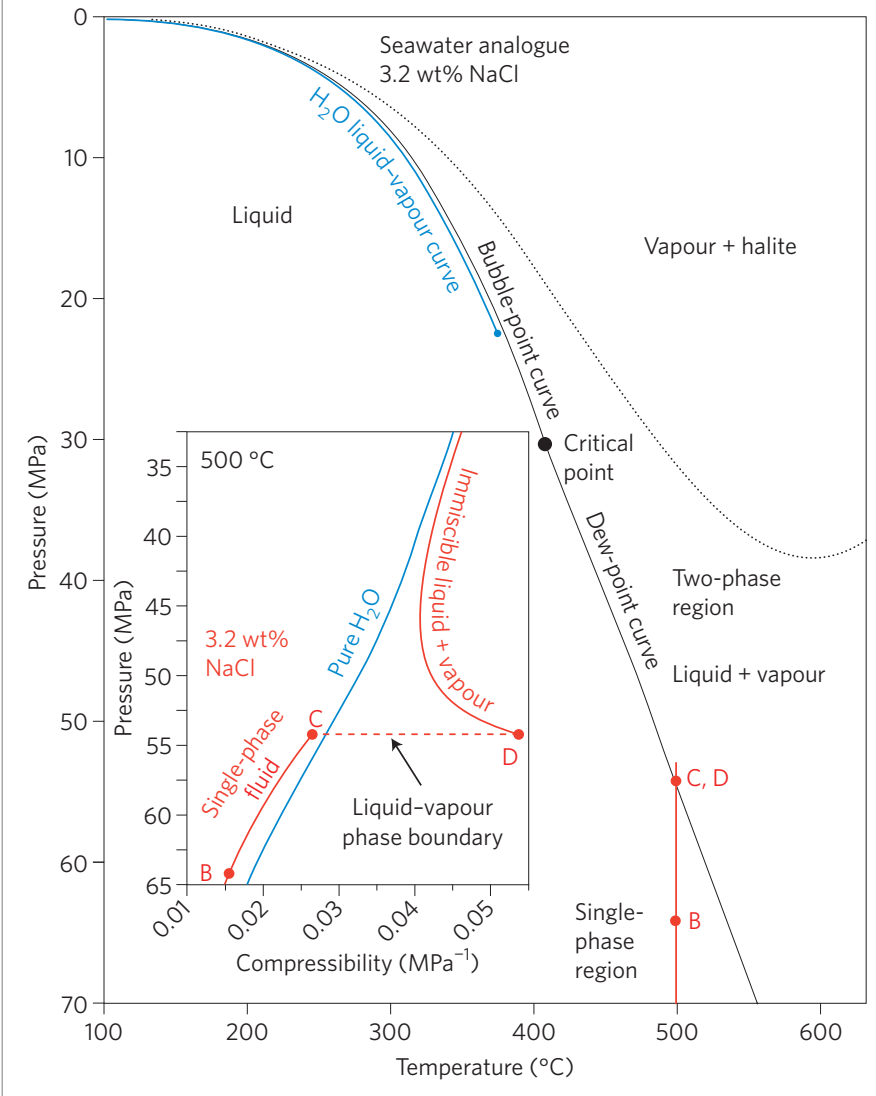

Figure 3

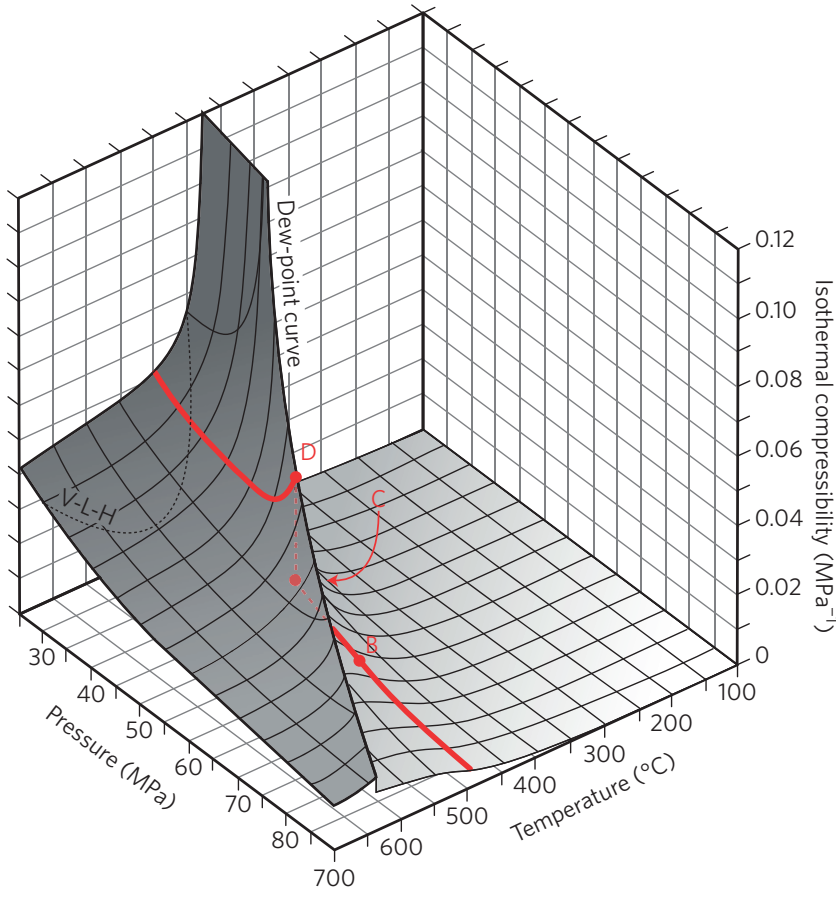

